\title{
Scrutiny Of Chemical Surfactants (n-Heptane, Polyimide, PVA, PVP, SDS) Based CdO Nanoparticles For The Application Of Solar Radiation Photocatalytic And Antimicrobial Activities
}

Gopi Somasundaram ( $\nabla$ ssgopi1992@gmail.com )

Sri Ramakrishna Mission Vidyalaya College of Arts and Science Jayaprakash $\mathbf{R}$

Sri Ramakrishna Mission Vidyalaya College of Arts and Science

\section{Research Article}

Keywords: n-heptane, Polyimide, PVA, PVP, SDS

Posted Date: May 6th, 2021

DOl: https://doi.org/10.21203/rs.3.rs-488707/v1

License: (a) (1) This work is licensed under a Creative Commons Attribution 4.0 International License. Read Full License 


\section{Abstract}

The chemical surfactant-based synthesis route is the $\mathrm{C}-\mathrm{H}$-based aqueous method using to form the restrained shape of Cadmium Oxide (CdO) nanoparticles. The effect of different weight percentages of $\mathrm{n}$ HEPTANE, POLYIMIDE, PVA, PVP, SDS in the preparation of CdO nanoparticles is studied. The surfactants are highly influenced by particle size variation and morphology gets changed. The role of surfactant is not produced any structural change apart from the particle size which is the advantageous part of the surfactant-based synthesis. The particle sizes from X-ray diffraction (XRD) analysis were found that there is a decrease in particle size from 54 to $92 \mathrm{~nm}$ when using the artificial chemical additives. The firmness of the CdO nanoparticles synthesized with help of chemical surfactants was characterized by UV-vis Diffused Reflectance Spectrometer (DRS), Fourier Transformer inferred (FT-IR), and photoluminescence studies. The photocatalytic activity and antimicrobial activity is investigated on using the chemical surfactant-based CdO nanoparticles as catalyst under Solar irradiation and zone inhibition method respectively.

\section{Introduction}

There are numerous numbers of attempts made on synthesizing nanostructured semiconductor materials. The semiconductor materials are becoming a pioneer in a large number of applications, like photonics, optoelectronics, photoluminescent devices, magnetic storage devices, photodetectors, chemical sensors, light-emitting diodes, logic gates, and electron transistors [6]. The optical and electrical properties of the semiconductor materials are supported for fabricating most of these devices. Also few of these materials possess photocatalytic activity $[7,8]$. The photocatalytic solution from water using a semiconductor material as a catalyst has been attracted researchers to give a solution for the global energy and environmental problems [9].

The outlet of nanomaterial synthesis with particular morphology and size is the great interest to the nanoworld [10]. This can be achieved by the researchers using polymeric materials in the synthesis. This preparation method helps to produce metal oxide nanoparticles with specific properties. The synthesis of $\mathrm{CdO}$ nanoparticles with the help of surfactants can be reduced long reaction times and also enhance crystallinity [2]. In this aspect, the surfactant plays an important role in $\mathrm{CdO}$ nanoparticle preparation. Polymeric materials like $n$-heptane $\left(\mathrm{C}_{7} \mathrm{H}_{16}\right)$, polyimide $\left(\mathrm{C}_{35} \mathrm{H}_{28} \mathrm{~N}_{2} \mathrm{O}_{7}\right), \mathrm{PVA}\left(\mathrm{C}_{2} \mathrm{H}_{4} \mathrm{O}\right), \mathrm{PVP}\left(\mathrm{C}_{8} \mathrm{H}_{14} \mathrm{O}_{2}\right)$, and $\mathrm{SDS}\left(\mathrm{C}_{18} \mathrm{H}_{29} \mathrm{NaO}_{3} \mathrm{~S}\right)$ are used for $\mathrm{CdO}$ nanoparticle preparation. This stage deals with the influence of the above surfactants to form the different morphology of CdO nanoparticles.

\section{Experimental Details}

The cadmium nitrate [Cd(NO3)2]. $6 \mathrm{H} 2 \mathrm{O}$, Ammonium hydroxide $(\mathrm{NH} 4 \mathrm{OH})$, n-heptane, and deionized water were chosen as raw materials for $\mathrm{CdO}$ nanoparticle preparation. $0.2 \mathrm{M}$ of [Cd(NO3)2].6H2O was prepared by using $150 \mathrm{ml}$ deionized water. The $\mathrm{NH} 4 \mathrm{OH}$ solution was added drop by drop in the above precursor solution using a magnetic stirrer. This solution was stirred at 3hours. The $\mathrm{pH}$ was maintained at 8 . Then 
separate beaker of $0.5 \mathrm{ml}$ of $\mathrm{n}$-heptane solution was made up into $10 \mathrm{ml}$ using deionized water. This surfactant solution was added drop-wise into the above precursor solution using a burette. Then these two solutions were stirred at 2 hours at constant temperature for $800 \mathrm{C}$. The black-brown colored powder was obtained as the final yield. This obtained yield was annealed at a constant temperature of $400 \mathrm{oC}$ at 4 hours. A similar procedure was repeated for other polymeric surfactants for other four surfactants such as Polyimide, Poly Vinyl Alcohol, Poly Vinyl Pyrrolididone, and Sodium Dodecyl Sulfate in the preparation of CdO nanoparticles.

\section{Results And Discussion}

\subsection{XRD analysis}

Figure 1(a-e) shows the XRD pattern of CdO nanoparticles prepared under four different surfactants such as n-heptane, polyimide, PVA, PVP, and SDS. The spectrum of the samples indicates the strong diffraction peaks at the angle as $33.10,38.40,55.40,66.0 \mathrm{o}$ and $69.3 \mathrm{o}$. The corresponding reflection peaks belong to the (hkl) values (110), (200), (220), (311), and (222) [JCPDS 05-0640]. These peaks belong to the simple cubic structure [3].The main peak of 33.10 of (111) crystallographic plane, which predominantly specifies the good crystalline nature for all the surfactant-based $\mathrm{CdO}$ nanoparticles. There are no additional diffraction peaks for representing other spices in the samples. It confirmed that these prepared cadmium oxide nanoparticles with the help of $n$-heptane, polyimide, PVA, PVP, and SDS are free from impurities. The crystallinity level of $\mathrm{CdO}$ nanoparticles of chemical surfactant of $\mathrm{n}$-heptane during the preparation is helped well to achieve good crystallinity in a curve (a) in Fig [1]. The influence of the next surfactant of polyimide for the preparation of $\mathrm{CdO}$ nanoparticles is also analyzed from the XRD pattern and it is shown in the curve (b) of Fig. 1(b). The reflection peaks of polyimide-based CdO nanoparticles are observed as (111), (200), (220), (311), and (222) which is also indicated with good crystalline nature. Similar peaks such as (111), (200), (220), (311), and (222) are observed for CdO nanoparticles prepared under nheptane and polyimide-based samples the curve (c, $d$, and e) are also possessed similar hkl value and indicate the crystalline nature of the sample. The change in crystallite size is varied for all the samples. This change is occurred due to the influence of chemical surfactants like $n$-heptane, polyimide, PVA, PVP, and SDS. These chemical surfactants are played as a capping agent [4] and decreased the grain size. The addition of these chemical polymeric surfactants helps to give the confirmed environment for the nucleation of growth of particles. The sharp diffraction peaks at 33.1 oand 38.40 indicated that the crystallite size of $\mathrm{CdO}$ nanoparticles is very small. The remaining diffraction peaks (55.40,66.0o, and 69.3o) indicate the high crystalline. The average particle size of the CdO nanoparticles is determined using Debye-Scherrer's formula [12]. The crystallite sizes are predicted as $70 \mathrm{~nm}$ for $\mathrm{n}$-heptane based CdO nanoparticles, $84 \mathrm{~nm}$ for polyimide-based CdO nanoparticles, $89 \mathrm{~nm}$ for PVA-based CdO nanoparticles, $54 \mathrm{~nm}$ for PVP-based CdO nanoparticles, and $71 \mathrm{~nm}$ for SDS based CdO nanoparticles. The usage of PVP as surfactant is well to form the less particle size than the other above-mentioned surfactants.

\subsection{UV-Vis-DRS Spectra}


Figure 2(a-e) shows the UV absorption spectra of CdO nanoparticles prepared under four different surfactants such as n-heptane, polyimide, PVA, PVP, and SDS. The UV absorption spectrum of n-heptane based CdO nanoparticles shown a peak in the UV region but the absorption band edge was gradually decreased compared to other spectra. The surfactants like n-heptane, polyimide, PVA, PVP, and SDS in $\mathrm{CdO}$ nanoparticles formation have indicated the same band at $240 \mathrm{~nm}$. This occurrence of absorption at $240 \mathrm{~nm}$ is due to the intrinsic bandgap absorption of $\mathrm{CdO}$ nanoparticles due to the electron transitions from the valence band to the conduction band (Cd3d -02p) [5]. Further, the adding of chemical surfactant solutions of $n$-heptane, polyimide, PVA, PVP, and SDS possess a strong absorption band in the visible region at $516 \mathrm{~nm}$ within an absorption edge of $400-800 \mathrm{~nm}$. The surfactants-based CdO nanoparticles lead to a gradual increase in absorption intensity. The various surfactants which obtaining the different absorption of the CdO nanoparticles are identified from these spectra. The reflectance $(R)$ is taken from absorption by Kubelka-Munk function $F(R)$ [6].

The bandgap energies of $n$-heptane, polyimide, PVA, PVP, and SDS-based CdO nanoparticles of samples are predicted from the DRS spectra and it is shown in Fig. 3(a-e). The optical bandgap energy value varies are $2.37 \mathrm{eV}$ for $\mathrm{n}$-heptane $\mathrm{CdO}$ nanoparticles $2.28 \mathrm{eV}$ for polyimide CdO nanoparticles, $2.21 \mathrm{eV}$ for PVA CdO nanoparticles, $2.39 \mathrm{eV}$ for PVP CdO nanoparticles and $2.30 \mathrm{eV}$ for SDS CdO nanoparticles respectively. A good agreement of the bandgap energy value with standard CdO nanoparticles is found for these samples [7]. This process of change in a bandgap due to chemical surfactants is happened because of surface modification of $\mathrm{CdO}$ nanoparticles. Thus, this difference in bandgap energy (Eg) value is caused only by various chemical surfactants. The increase in bandgap energy value for PVPbased CdO nanoparticles has also evidenced the decrease of particle size [21].

\subsection{PL Spectra}

Figure 4(a-e) shows the PL spectra of CdO nanoparticles prepared under various surfactants such as nheptane, polyimide, PVA, PVP, and SDS. The $n$-heptane based CdO nanoparticles of luminescence spectrum of the curve (a) in Fig. 4 show (a) strong emission peak at $310 \mathrm{~nm}$ corresponding to the UV region of CdO nanoparticles. Similarly, luminance spectra of the curve (b-e) the polyimide, PVA, PVP, and SDS-based CdO nanoparticles showed in Fig. 4 (b-e). This spectrum shows the emission peak at $312 \mathrm{~nm}$ with excitation of $250 \mathrm{~nm}$ and slight variation is observed in wavelength. A small shift appears for other surfactants such as PVA, PVB, and SDS than $n$-heptane. This shift can be revealed the change in surface morphology of $\mathrm{CdO}$ nanoparticles [8]. This emission is assigned to the transition between photogenerated holes and singly ionized oxygen vacancies [9]. The second prominent peak at $372 \mathrm{~nm}$ and 375 $\mathrm{nm}$ belongs to the violet region of curve (c) and curve (d). The prominent peak in the curve (b) and (e) is observed only for the polyimide and SDS-based CdO nanoparticles. These peaks reveal the smoothness of the surface of spherical particles with no crystal defects in the crystal lattice [10].

\subsection{FT-IR Spectra}

Figure 5(a-e) shows the FT-IR spectrum of CdO nanoparticles prepared under various surfactants such as n-heptane, polyimide, PVA, PVP, and SDS. These samples display prominent transmittance spectra with respective significant vibration bands in the IR region of 4000-1- $400 \mathrm{~cm}-1$. The curve shows strong and 
weak bands at $3782 \mathrm{~cm}-1,2348 \mathrm{~cm}-1,1590 \mathrm{~cm}-1,1382 \mathrm{~cm}-1$, and $433 \mathrm{~cm}-1$ emerge all the samples. The strong band at $3782 \mathrm{~cm}-1$ is $\mathrm{O}-\mathrm{H}$ stretching vibration of the hydroxyl group is appeared in all these samples [11]. The presence of $\mathrm{O}-\mathrm{H}$ vibration in the calcinated samples may be due to the adsorption of moisture in the atmosphere. The tiny bend at $2348 \mathrm{~cm}-1$ correspond to the $\mathrm{O}=\mathrm{C}=\mathrm{O}$ stretching vibrations of instrumental carbon-di-oxide [12]. The band located at $1590 \mathrm{~cm}-1$ is represented as the $\mathrm{C}-\mathrm{C}$ stretching vibration of aromatics in the chemical surfactants [13]. The sharp band at $1382 \mathrm{~cm}-1$ is indicated surface coated carbon present in the annealed samples [14]. The trace of carbon is evidenced in the EDAX spectra. This carbon procedure is unavoidable while preparing surfactant-based nanoparticles [15]. The main metal band region at $433 \mathrm{~cm}-1$ is indicating the vibration between cadmium (Cd) and oxygen (0) [15].

\subsection{FESEM and HRTEM analysis}

Figure 6.1(a1-a4) shows the FESEM and HRTEM images of $n$-heptane based CdO nanoparticles. This nheptane is the composition of carbon and hydrogen molecules. Figure 6.1(a1) shows the FESEM image of $n$-heptane based CdO nanoparticles. This image depicts a huge bunch of nanowires with some smooth agglomerated spherical particles. These nanowires and spherical particles appear as a mixture of both. It is visualized from the following in the HRTEM image. Figure 6.1(a2) shows the HRTEM image of h-heptane based $\mathrm{CdO}$ nanoparticles. This image exhibits specifically the formation of spherical particles with very fine nanowires are formed. The average diameter of the spherical particle is $37 \mathrm{~nm}$ to $74 \mathrm{~nm}$ and the width of the nanowire is $3 \mathrm{~nm}$. These sizes are shown in TEM images. Figure 6.1(a3) shows the higher magnification of the two spherical CdO nanoparticles [16] already reported CdO nanoparticles prepared using n-heptane as a surfactant to the preparation of $\mathrm{CdO}$ nanoparticles. The author achieved very fine nanowires in the size of 25-30nm. Figure 6.1 (a4) shows the SAED pattern with bright and dark spots of $\mathrm{CdO}$ nanoparticles. This image reveals good crystallinity and matches well with the diffraction plans of the respective XRD spectrum.

Figure 6.2(b1-b4) shows the FESEM and HRTEM images of polyimide-based CdO nanoparticles. Figure 8.3.6 (b1) shows the FESEM image of CdO nanoparticles prepared using polyimide. This image shows the almost equally distributed spherical structure of CdO nanoparticles. Figure 6.2 (b2) shows the HRTEM image of polyimide-based CdO nanoparticles predicts spherical-shaped nanoparticles with a fine edge. The diameter of the spherical particles calculated as $76 \mathrm{~nm}$. Figure 6.2 (b3) shows another image of the sample with higher magnification of the two spherical particles attached one to another. This image showed that the polyimide surfactant protects from more agglomeration of $\mathrm{CdO}$ nanoparticles. Figure 6.2 (b4) shows the SAED pattern of dark and bright rings. It shows significant single crystallinity of CdO nanoparticles and also these spots have good agreement with XRD hkl planes.

Figure 6.3(c1-c4) shows the FESEM and HRTEM images of PVA-based CdO nanoparticles. Figure 6.3 (c1) shows the FESEM image of PVA-based CdO nanoparticles. This image displays a conglomeration of bulk $\mathrm{CdO}$ nanoparticles with very few plate structures. Also, this image shows carbon presence as noticed from FT-IR with CdO nanoparticles. It is nothing but the trace of the surfactant even after annealing 
treatment. It also reflects the polymeric nature of PVA surfactant. Figure 6.3 (c2) shows the HRTEM image of CdO nanoparticles. This image reveals small spherical particles combined to form a DNA-like structure.

Figure 6.3 (c3) shows the higher magnification of spherical particles with an average size at $19 \mathrm{~nm}-55$ nm. Figure 6.3 (c4) shows the SAED image of CdO nanoparticles. It also reveals that the polycrystalline of the CdO nanoparticles with simple cubic structure [17]. The bright dots over the circular ring indicate corresponding plane such as (110), (200), (220), (311), and (222) which is identified from XRD pattern sample $C$. the agglomeration is more between the spherical particles than other surfactants used here for the PVA is not much supported to prevent agglomeration like other chemical surfactants such as nheptane and polyimide.

Figure 6.4 (d1-d4) shows the FESEM and HRTEM images of PVP-based CdO nanoparticles. Figure 6.4 (d1) shows the FESEM image of PVP surfactants-based CdO nanoparticles. This image shows agglomerated spherical-shaped $\mathrm{CdO}$ nanoparticles. It appears like a coral surface. Most of the particles are irregular with some spherical-shaped particles. Figure 6.4 (d2) shows the HRTEM image of PVP-based $\mathrm{CdO}$ nanoparticles. This image exhibits coral shape with embedded spherical particles of the average particle size of $78 \mathrm{~nm}$. It creates a network of CdO spherical particles. Figure 6.4 (d3) shows the next magnification of $\mathrm{CdO}$ nanoparticles which displays particles combines to another like chain pasted structure. This combination may be occurring due to PVP surfactant. Figure 6.4 (d4) shows the SAED pattern of dark and bright fringes circular rings indicated good polycrystalline nature.

Figure 6.5(e1-e4) shows the FESEM and HRTEM images of SDS-based CdO nanoparticles. The FESEM image of Fig. 6.5 (e1) shows more number of spherical and platelet-shaped CdO nanoparticles with smooth edges. The HRTEM image of Fig. 6.5 (e2) shows the spherical and square platelets shaped by $\mathrm{CdO}$ nanoparticles. The size of particles is measured from this image is between $71 \mathrm{~nm}$ and $92 \mathrm{~nm}$. Also, this image confirms less agglomeration. Figure 6.5 (e4) shows the next magnification of the above image (e3). This image shows the hexagonal crystalline form with smooth cutting edges. Figure 6.5 (e4) shows the SAED pattern of CdO nanoparticles with significant polycrystalline nature. The bright spots representation in the pattern has good agreement with the crystallinity as recorded from XRD spectra.

\subsection{EDAX analysis}

Figure 7(a-e) shows the EDAX spectra of n-heptane, polyimide, PVA, PVP, and SDS-based CdO nanoparticles. The compositions of elements present in the prepared surfactant-based CdO samples are identified. The well-maintained stoichiometry is identified for most of the samples. It also reveals that the synthesized CdO nanoparticles using surfactants like polyimide and PVP have shown the metallic ions impurity as Au. The presence of $\mathrm{Au}$ in the spectra is identified as the golden grid which is used as a sample holder. The emission of strong signals belongs to cadmium and oxygen as $84.79 \%$ and $10.27 \%$ for n-heptane based CdO nanoparticles, $42.18 \%$ and $17.28 \%$ for polyimide-based CdO nanoparticles, $82.91 \%$ and $10.8 \%$ for PVA based CdO nanoparticles, $75.35 \%$ and $22.69 \%$ for PVPbased CdO nanoparticles $84.79 \%$ and $10.27 \%$ for SDS based CdO nanoparticles. The presence of the elemental composition of these samples is listed in Table 1. 
Table 1

shows the composition of elements of various surfactant based CdO nanoparticles.

\begin{tabular}{|c|c|c|c|}
\hline Samples & Element & Weight \% & Atomic \% \\
\hline \multirow[t]{3}{*}{ CdO-n-heptane } & $\mathrm{CK}$ & 4.94 & 22.75 \\
\hline & $\mathrm{OK}$ & 10.27 & 35.52 \\
\hline & $\mathrm{Cd} \mathrm{L}$ & 84.79 & 41.73 \\
\hline \multirow[t]{4}{*}{ CdO-Polyimide } & $\mathrm{CK}$ & 30.16 & 62.48 \\
\hline & $\mathrm{OK}$ & 17.28 & 26.87 \\
\hline & Au M & 10.38 & 1.31 \\
\hline & $\mathrm{Cd} \mathrm{L}$ & 42.18 & 9.34 \\
\hline \multirow[t]{3}{*}{ CdO- PVA } & $\mathrm{CK}$ & 6.29 & 27.04 \\
\hline & $\mathrm{OK}$ & 10.8 & 34.85 \\
\hline & $C d L$ & 82.91 & 38.1 \\
\hline \multirow[t]{3}{*}{ CdO- PVP } & $\mathrm{OK}$ & 22.69 & 67.59 \\
\hline & $\mathrm{Au} \mathrm{M}$ & 1.96 & 0.47 \\
\hline & $\mathrm{Cd} \mathrm{L}$ & 75.35 & 31.94 \\
\hline \multirow[t]{3}{*}{ CdO-SDS } & $\mathrm{CK}$ & 4.94 & 22.75 \\
\hline & $\mathrm{OK}$ & 10.27 & 35.52 \\
\hline & $\mathrm{Cd} \mathrm{L}$ & 84.79 & 41.73 \\
\hline
\end{tabular}

\subsection{Photocatalytic activity}

The photocatalytic activity of various surfactants-based $\mathrm{CdO}$ nanoparticles was investigated for the aqueous solution of the chromophoric structure of MB dye under solar light irradiation. The characteristics absorption peak of MB dye at $\sim 664 \mathrm{~nm}$ is fixed to monitor the photo degeneration of dye molecules. Figure 9. (A-E) shows the degradation of MB dye with surfactant-based CdO nanoparticles at a different concentration under the wavelength, $\lambda=365 \mathrm{~nm}$. From Fig. 9. (A-E) it is clear that after exposing the mixed solution of MB dye and photocatalyst such as $\mathrm{CdO}$ nanoparticle samples $\mathrm{A}-\mathrm{n}$ heptane, B- Polyimide, C- PVA, D-PVB, and E- SDS under solar radiation. Each sample MB solution is irradiated under solar irradiation for $120 \mathrm{~min}$. The without extract $\mathrm{CdO}$ nanoparticles sample n-heptane degrade the MB dye up to $83 \%$, similarly, the degradation is observed in MB dye for $95.4 \%$ for polyimide, $86 \%$ for PVA, $90 \%$ for PVB, and $78 \%$ for SDS are observed from the solar light irradiation. The degradation of MB dye is not observed in the absence of photocatalyst. The SDS surfactant-based CdO 
nanoparticles show only $78 \%$ of degradation. The highest level the $95.4 \%$ of polyimide and $90 \%$ of PVB. This result confirms that the spherical-shaped morphology like polyimide and PVB based CdO nanoparticles have shown an enhancement in intrinsic photocatalytic activity under solar light irradiation of their $\mathrm{CdO}$ nanoparticles. The comparison of degradation efficiency was made by considering the almost similar intensity of solar radiation [20].

\subsection{Antibacterial and Antifungal activities}

The antimicrobial activity of various surfactants-based CdO nanoparticles was investigated for an antibacterial agent were tested for respective antibacterial towards both gram-positive (Staphylococcus aureus) and gram-negative (Escherichia coli) bacteria. The inhibition of CdO nanoparticles over the bacterial and fungal are discussed as follows. The gram-positive bacteria cell wall is a peptidoglycan molecule. The gram-positive bacteria cell consists of a thick wall. As the $\mathrm{Cd} 2+$ ions are positively charged and peptidoglycan is negatively charged. So there is an electrostatic [21] attraction between these positive and negative ions. So, more positive $\mathrm{Cd} 2+$ ions are interacting over the surface of the peptidoglycan. The more accumulation of $\mathrm{Cd} 2+$ ions over the surface damages the cell wall and diffuses into the cells. In this way, the cell wall or membrane gets damaged.

Figure 9. (A-D) shows that the zone of inhibition for gram-positive bacteria Staphylococcus aureus is observed for the samples n-heptane, polyimide, PVA, PVB, and SDS. similarly, the zone of inhibition of $\mathrm{CdO}$ nanoparticles on gram-negative bacteria of Escherichia coli is observed for the samples n-heptane, polyimide, PVA, PVB, and SDS. Table 2 summarizes the antibacterial activity of extracts-based CdO nanoparticles. Based on the zone of inhibition, polyimide-based CdO nanoparticles proved the highest antibacterial activity against Staphylococcus aureus and Escherichia coli. The result from the antibacterial activity is presumed from the inhibition as low activity over the bacterial medium. Thus, the zones around $\mathrm{CdO}$ nanoparticles are formed when the growth of the bacteria is stopped by CdO nanoparticles cogently [22].

Table 2

Summarizes the zone inhibition values of chemical surfactants based CdO nanoparticles

\begin{tabular}{|llllll|}
\hline $\begin{array}{l}\text { Surfactant based } \\
\text { CdO nanoparticles }\end{array}$ & $\begin{array}{l}\text { Sample } \\
\text { code }\end{array}$ & $\begin{array}{l}\text { Staphylococcus } \\
\text { aureus(mm) }\end{array}$ & $\begin{array}{l}\text { Escherichia } \\
\text { Coli(mm) }\end{array}$ & $\begin{array}{l}\text { Candida } \\
\text { albicans(mm) }\end{array}$ & $\begin{array}{l}\text { Aspergillus } \\
\text { niger(mm) }\end{array}$ \\
\hline n-heptane & A1 & 7 & 18 & 6 & 9 \\
\hline Poly imide & B1 & 11 & 19 & 7 & 4 \\
\hline PVA & C1 & 8 & 14 & 4 & 3 \\
\hline PVP & D1 & 6 & 15 & 4 & 5 \\
\hline SDS & E1 & 7 & 17 & 6 & 8 \\
\hline
\end{tabular}

Antifungal properties of surfactant-based $\mathrm{CdO}$ nanoparticles were also examined against selected fungal test pathogens such as Candida Albicans and Aspergillus niger are shown in Fig. 9. (A-D) shows the zone 
of inhibition of $\mathrm{CdO}$ nanoparticles concerning all pathogens are listed in Table 2. This test is proved that CdO nanoparticles possessed good antifungal activity towards Candida Albicans and Aspergillus niger is observed as n-heptane, polyimide, PVA, PVB, and SDS. The predominant zone inhibition due to CdO nanoparticles over the antifungal activity is observed. These results confirmed that the chemical surfactant-based $\mathrm{CdO}$ nanoparticles showed significant antibacterial capability against gram-positive and gram-negative bacteria as well as good antifungal activities. The negative strain of the Escherichia coli is the best inhibition of bacterial study. Also tested by the fungal organism Candida albicans is the best inhibition value compared to the other organism of Aspergillus niger.

\section{Conclusion}

The water-soluble chemical surfactants of $n$-heptane, polyimide, PVA, PVP, and SDS are found as a major role in the synthesis of CdO nanoparticles. The XRD spectra show the different surfactants produces different crystallite size within the nano range. $P L$ spectra predict at $310 \mathrm{~nm}$ and $312 \mathrm{~nm}$. The bandgap value also resembles the particle size variation of $\mathrm{CdO}$ nanoparticles due to surfactants. FESEM and HRTEM image shows the formation of nanowires, spherical shaped smooth particles, DNA structure, and square platelets. The role of surfactants causes more agglomeration. Thus the effect of size reduction of particles is sustainable for the surfactants $n$-heptane, polyimide, PVP, and SDS except for PVA. The morphologic changes from polymeric material have created evidence and support for the morphological change. The photocatalytic activities of CdO nanoparticles prepared by different surfactants were tested under solar irradiation for $120 \mathrm{~min}$. The spherical-shaped morphology of the $\mathrm{CdO}$ nanoparticles shows the best performance in MB azo dye. In particular, n-heptane based CdO nanoparticles show only $95 \%$ of degradation. The highest degradation level of the $95 \%$ of polyimide and $90 \%$ of PVB are the sphericalshaped morphology and fine smooth surfaces. This spherical-shaped morphology leads to the more O-H stretching vibration and easily breaks the azo group. Other morphology of nanorod and DNA structure should not break the azo dye. So the degradation percentage is very less. Also, the previous researchers are proved the spherical morphology of the semiconducting oxide materials to the higher performance of a photocatalytic activity. Indeed, the other morphology like nanorods, agglomerated spherical particles also exhibited significant degradation compared to the other morphologies. The antibacterial study was tested both gram-positive (Staphylococcus aureus) and gram-negative (Escherichia coli) bacteria. The effective inhibition is occurred in the Escherichia coli and Staphylococcus aureus of antibacterial as well as in Candida albicans and Aspergillus niger of antifungal organism in the antimicrobial study. The different surfactant-based CdO nanoparticles proved their potential on zone inhibition of chemical-based CdO nanoparticles.

\section{Declarations}

\section{Conflict of Interest}

The author declared there is no conflict of interest. 


\section{References}

1. Kim, Bumjoon J., Joona Bang, Craig J. Hawker, Julia J. Chiu, David J. Pine, Se Gyu Jang, Seung-Man Yang, and Edward J. Kramer. "Creating surfactant nanoparticles for block copolymer composites through surface chemistry." Langmuir 23, no. 25 (2007): 12693-12703.

2. Chavanpatil, M. D., Khdair, A., Patil, Y., Handa, H., Mao, G., \& Panyam, J. (2007). Polymer-surfactant nanoparticles for sustained release of water-soluble drugs. Journal of pharmaceutical sciences, 96(12), 3379-3389.

3. Kvítek, L., Panáček, A., Soukupova, J., Kolář, M., Večeřová, R., Prucek, \& Zbořil, R. (2008). Effect of surfactants and polymers on stability and antibacterial activity of silver nanoparticles (NPs). The Journal of Physical Chemistry C, 112(15), 5825-5834.

4. Kim, D. K., Zhang, Y., Voit, W., Rao, K. V., \& Muhammed, M. (2001). Synthesis and characterization of surfactant-coated superparamagnetic monodispersed iron oxide nanoparticles. Journal of Magnetism and Magnetic Materials, 225(1-2), 30-36.

5. Guardia, P., B. Batlle-Brugal, A. G. Roca, Oscar Iglesias, M. D. P. Morales, C. J. Serna, A. Labarta, and X. Batlle. "Surfactant effects in magnetite nanoparticles of controlled size." Journal of Magnetism and Magnetic Materials316, no. 2 (2007): e756-e759.

6. Chen, Dong-Hwang, and Chih-Hsuan Hsieh. "Synthesis of nickel nanoparticles in aqueous cationic surfactant solutions." Journal of Materials Chemistry12, no. 8 (2002): 2412-2415.

7. Jana, Nikhil R., Latha Gearheart, and Catherine J. Murphy. "Seed-mediated growth approach for shape-controlled synthesis of spheroidal and rod-like gold nanoparticles using a surfactant template." Advanced Materials13, no. 18 (2001): 1389-1393.

8. Chakka, V. M., Baki Altuncevahir, Z. Q. Jin, Y. Li, and J. P. Liu. "Magnetic nanoparticles produced by surfactant-assisted ball milling." Journal of Applied Physics99, no. 8 (2006): 08 E912.

9. Liz-Marzán, Luis M., and Isabel Lado-Touriño. "Reduction and stabilization of silver nanoparticles in ethanol by nonionic surfactants." Langmuir 12, no. 15 (1996): 3585-3589.

10. Shukla, Nisha, Chao Liu, Paul M. Jones, and Dieter Weller. "FTIR study of surfactant bonding to FePt nanoparticles." Journal of Magnetism and Magnetic materials266, no. 1-2 (2003): 178-184.

11. Santra, Swadeshmukul, Rovelyn Tapec, Nikoleta Theodoropoulou, Jon Dobson, Arthur Hebard, and Weihong Tan. "Synthesis and characterization of silica-coated iron oxide nanoparticles in microemulsion: the effect of nonionic surfactants." Langmuir17, no. 10 (2001): 2900-2906.

12. Pal, Tarasankar, Tapan K. Sau, and Nikhil R. Jana. "Reversible formation and dissolution of silver nanoparticles in aqueous surfactant media." Langmuir13, no. 6 (1997): 1481-1485.

13. Liao, D. L., and B. Q. Liao. "Shape, size and photocatalytic activity control of TiO2 nanoparticles with surfactants." Journal of Photochemistry and Photobiology A: Chemistry187, no. 2-3 (2007): 363-369.

14. Müller, Rainer H., Dörte Rühl, Stephan Runge, Kai Schulze-Forster, and Wolfgang Mehnert.

"Cytotoxicity of solid lipid nanoparticles as a function of the lipid matrix and the

surfactant." Pharmaceutical research14, no. 4 (1997): 458-462. 
15. Singh, Chetana, Pradip K. Ghorai, Mark A. Horsch, Alicia M. Jackson, Ronald G. Larson, Francesco Stellacci, and Sharon C. Glotzer. "Entropy-mediated patterning of surfactant-coated nanoparticles and surfaces." Physical Review Letters99, no. 22 (2007): 226106.

16. Han, Yu, and Jackie Y. Ying. "Generalized fluorocarbon-surfactant-mediated synthesis of nanoparticles with various mesoporous structures." Angewandte Chemie117, no. 2 (2005): 292-296.

17. Petri, B., A. Bootz, A. Khalansky, T. Hekmatara, R. Müller, R. Uhl, J. Kreuter, and S. Gelperina. "Chemotherapy of brain tumour using doxorubicin bound to surfactant-coated poly (butyl cyanoacrylate) nanoparticles: revisiting the role of surfactants." Journal of Controlled Release117, no. 1 (2007): 51-58.

18. Calandra, P., M. Goffredi, and V. Turco Liveri. "Study of the growth of ZnS nanoparticles in water/AOT/n-heptane microemulsions by UV-absorption spectroscopy." Colloids and Surfaces $A$ : Physicochemical and Engineering Aspects160, no. 1 (1999): 9-13.

19. Esmaeilzadeh, Pouriya, Negahdar Hosseinpour, Alireza Bahramian, Zahra Fakhroueian, and Sharareh Arya. "Effect of ZrO2 nanoparticles on the interfacial behavior of surfactant solutions at air-water and n-heptane-water interfaces." Fluid Phase Equilibria361 (2014): 289-295.

20. Hota, G., Shikha Jain, and Kartic C. Khilar. "Synthesis of CdS-Ag2S core-shell/composite nanoparticles using AOT/n-heptane/water microemulsions." Colloids and Surfaces $A$ : Physicochemical and Engineering Aspects232, no. 2-3 (2004): 119-127.

21. Liveri, V. Turco, M. Rossi, G. D’Arrigo, D. Manno, and G. Micocci. "Synthesis and characterization of ZnS nanoparticles in water/AOT/n-heptane microemulsions." Applied Physics A69, no. 4 (1999): 369373.

22. Guo, Yongqiang, Xutong Yang, Kunpeng Ruan, Jie Kong, Mengyao Dong, Jiaoxia Zhang, Junwei Gu, and Zhanhu Guo. "Reduced graphene oxide heterostructured silver nanoparticles significantly enhanced thermal conductivities in hot-pressed electrospun polyimide nanocomposites." ACS applied materials \& interfaces11, no. 28 (2019): 25465-25473.

\section{Figures}




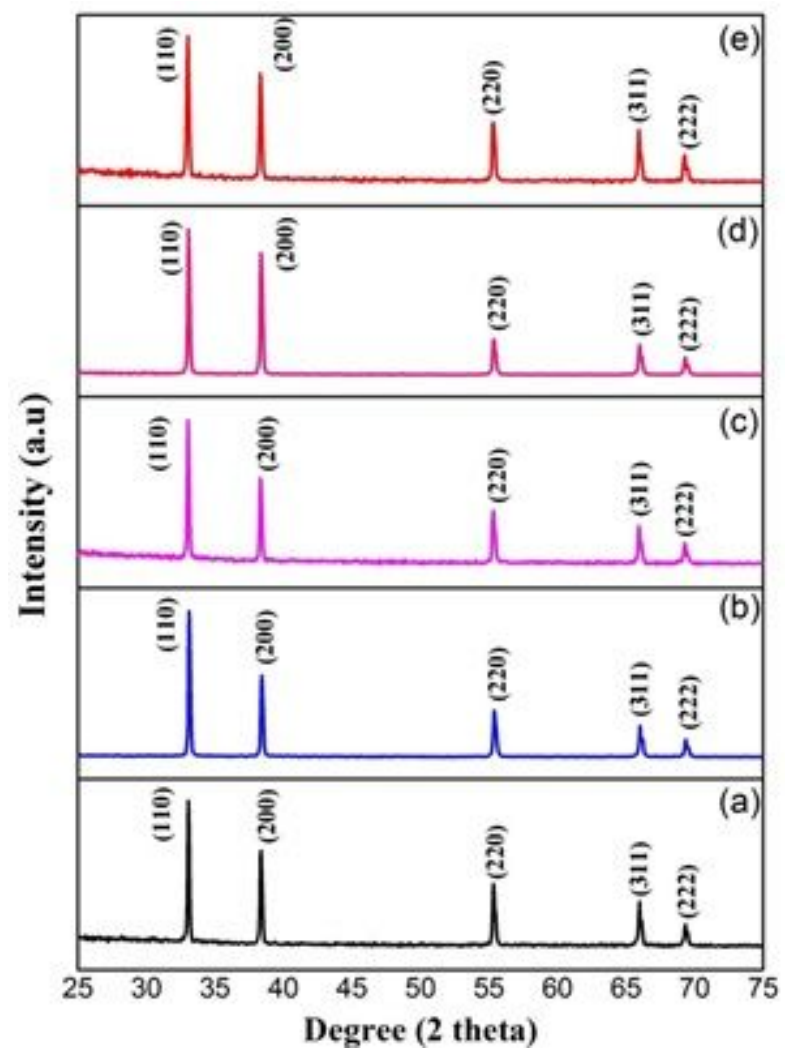

Figure 1

(a-e) shows the XRD Spectrum of surfactant based CdO nanoparticles

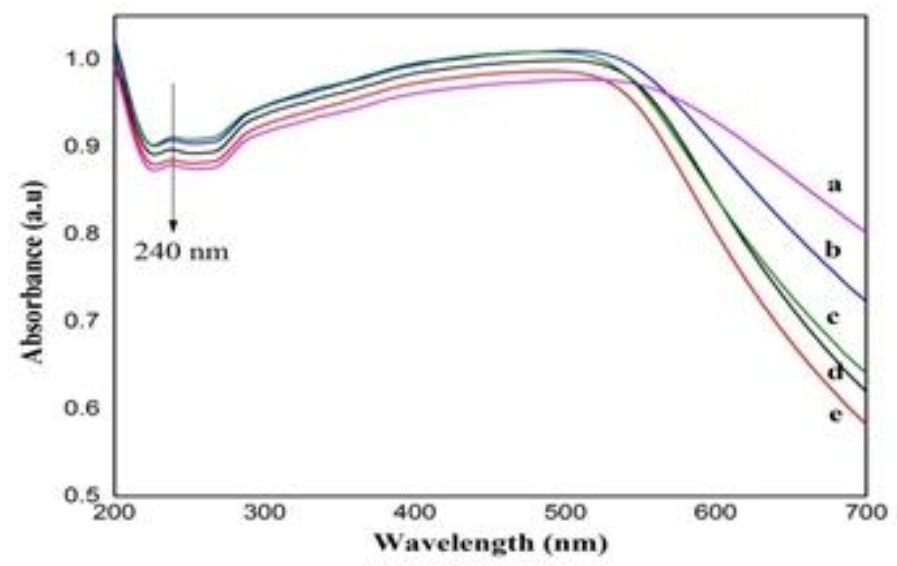

Figure 2

(a-e) shows the UV-absorption Spectrum of surfactant based CdO nanoparticles. 


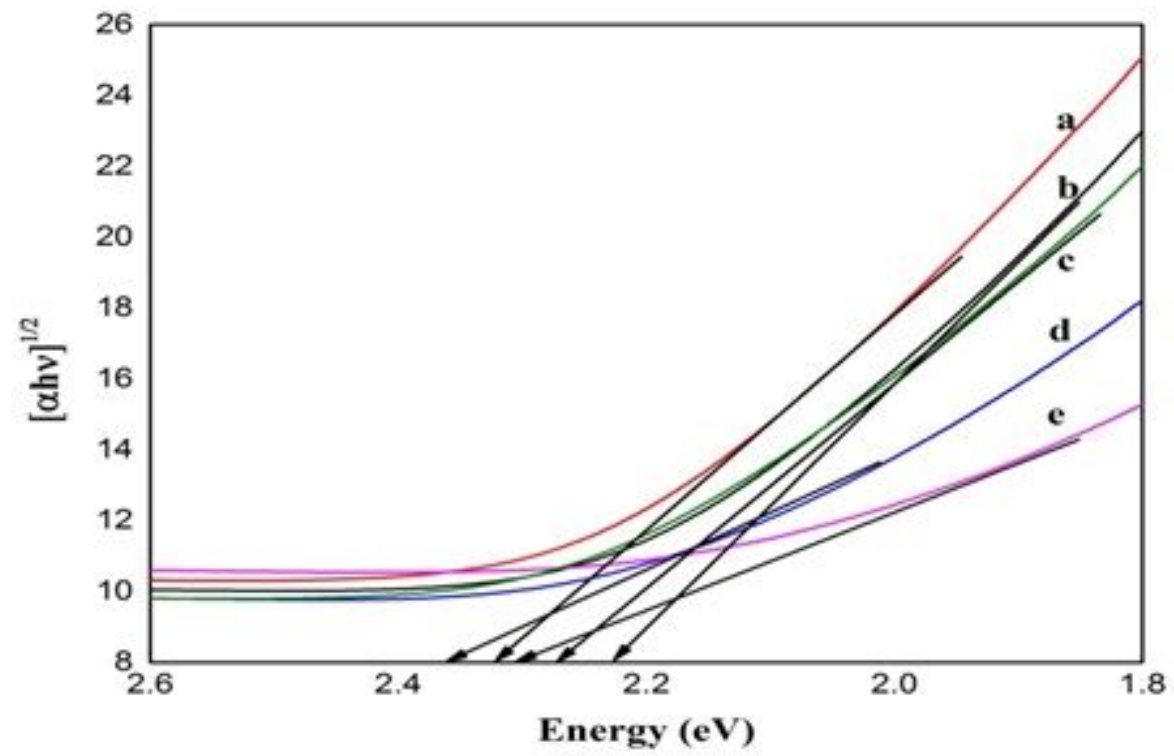

Figure 3

(a-e) shows the UV-DRS Spectrum of surfactant based CdO nanoparticles.

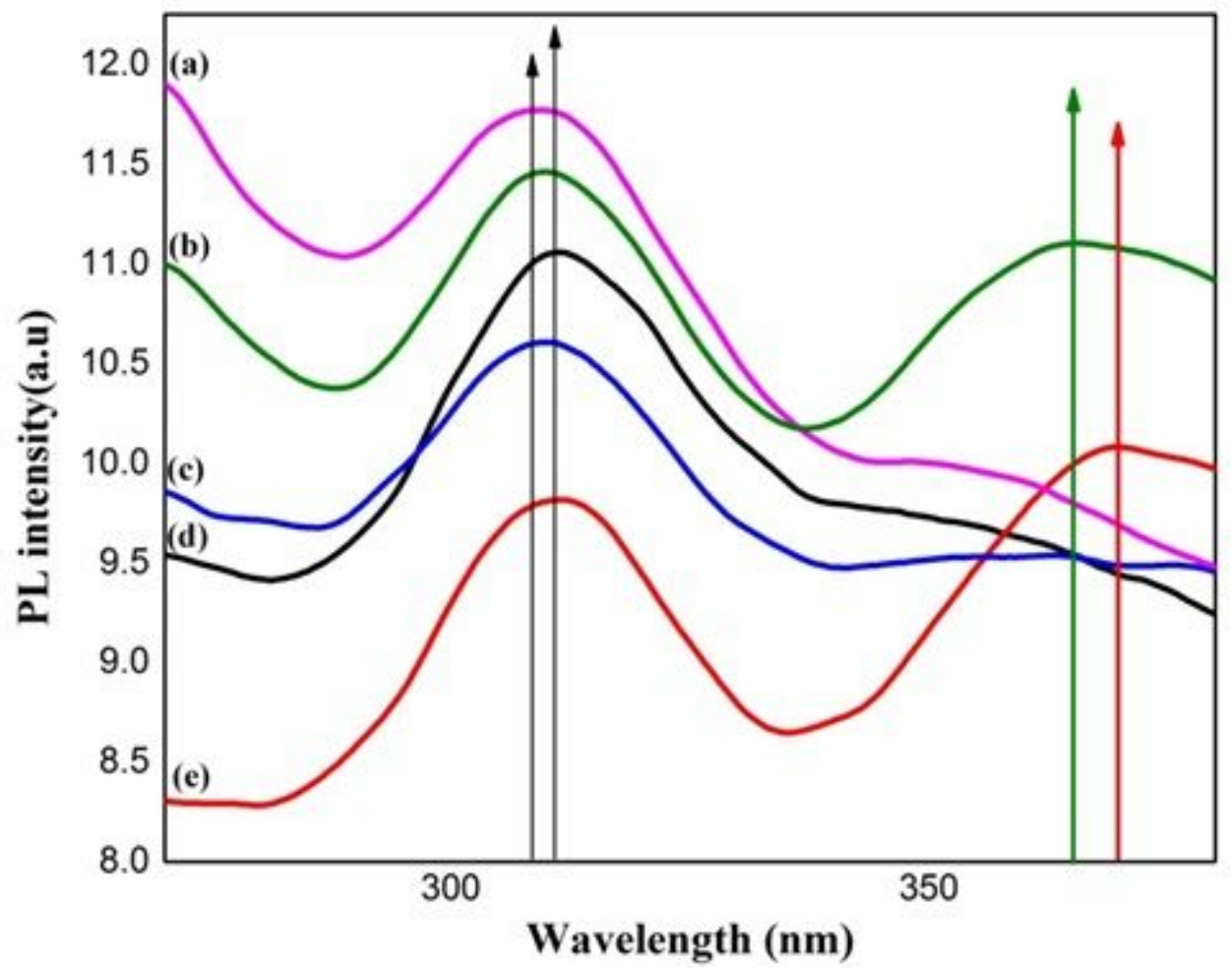

Figure 4

(a-e) shows the PL Spectrum of surfactant based CdO nanoparticles. 


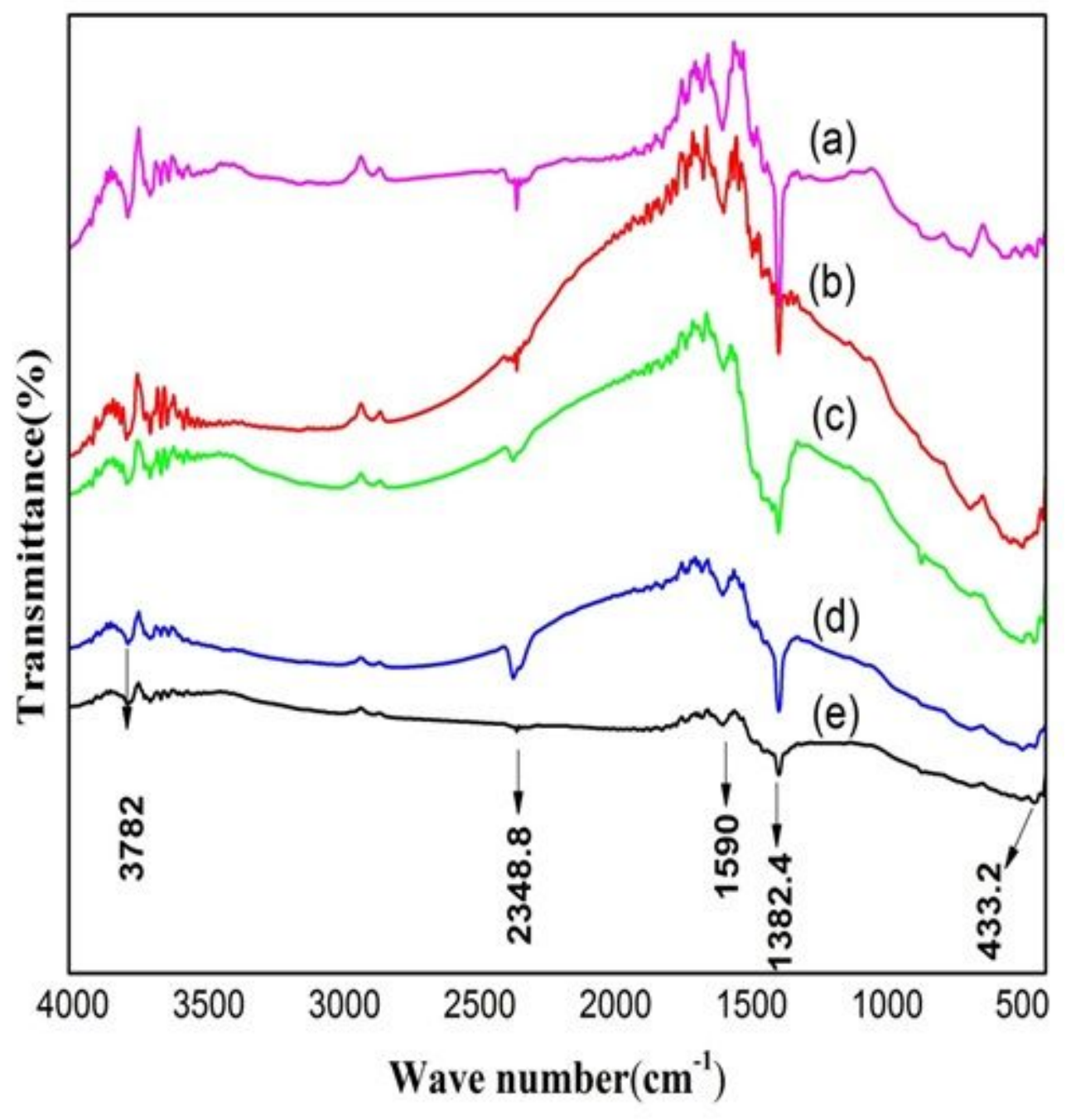

Figure 5

(a-e) shows the FT-IR Spectrum of surfactant based CdO nanoparticles. 

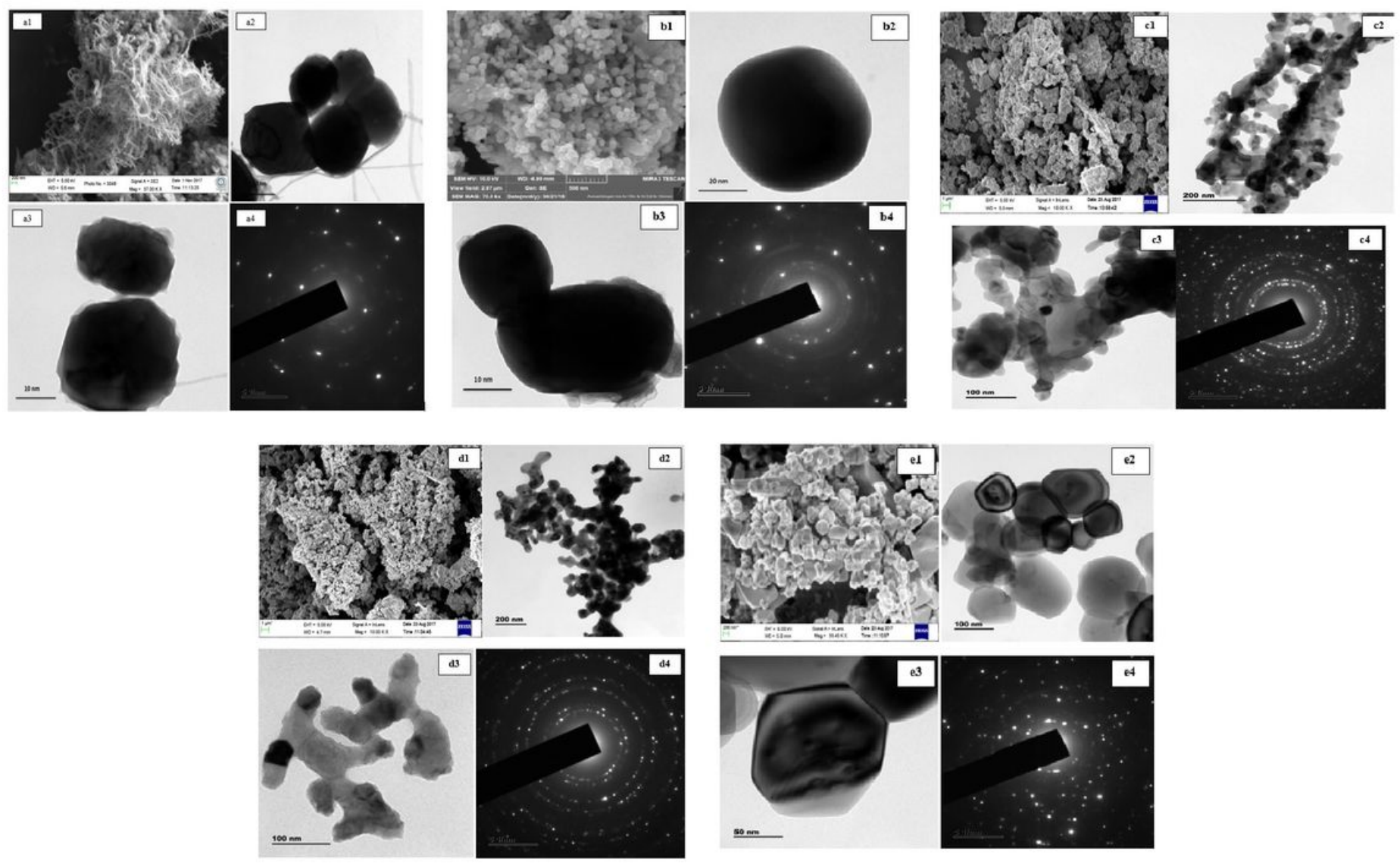

\section{Figure 6}

(a1-a4) shows the FESEM and HRTEM image of n-heptane based CdO nanoparticles. (b1-b4) shows the FESEM and HRTEM image of polyimide based CdO nanoparticles. (c1-c4) shows the FESEM and HRTEM image of PVA based CdO nanoparticles. (d1-d4) shows the FESEM and HRTEM image of PVP based CdO nanoparticles. (e1-e4) shows the FESEM and HRTEM image of SDS based CdO nanoparticles. 


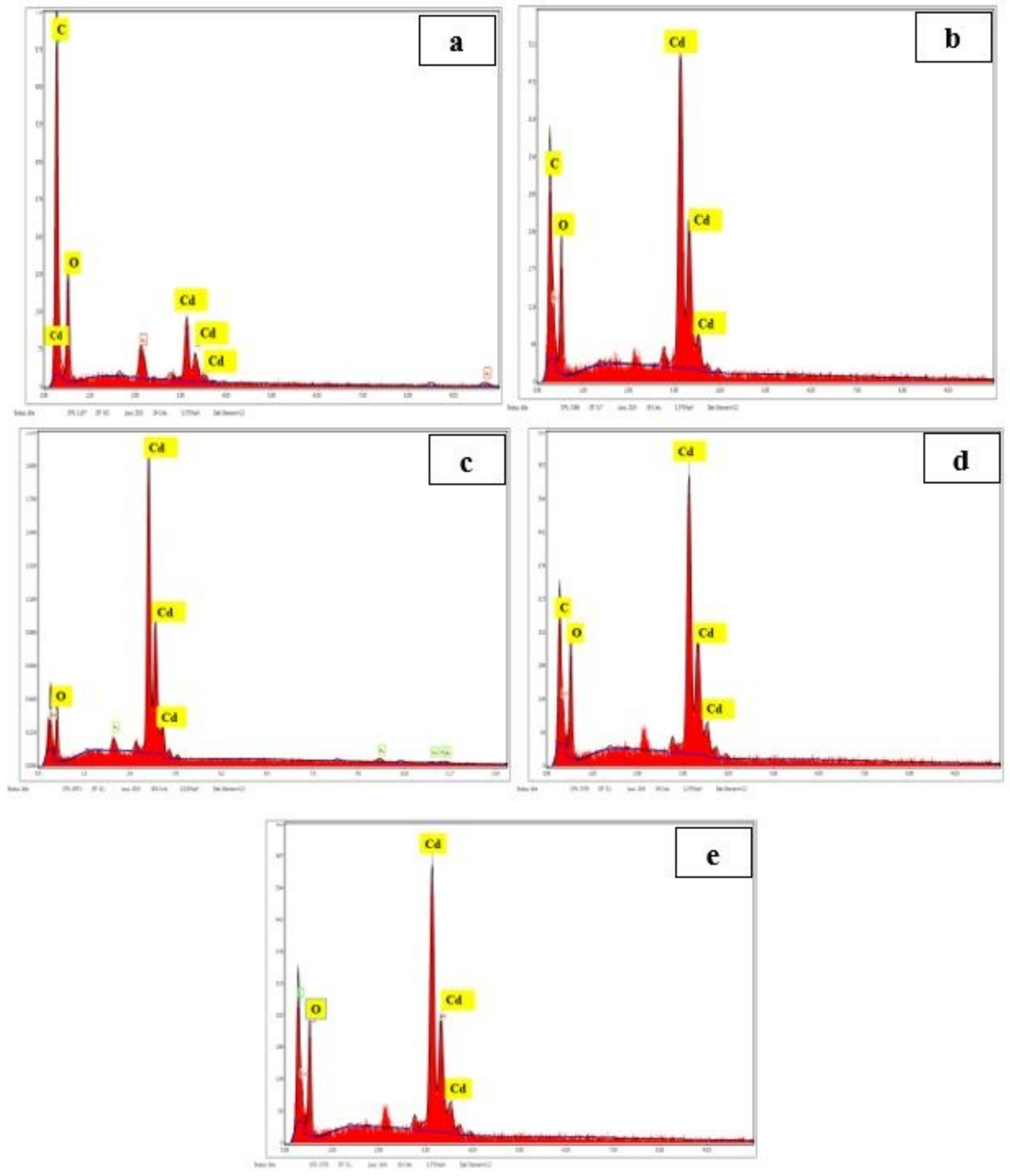

Figure 7

(a-e) shows the EDX spectrum of surfactant based CdO nanoparticles. 

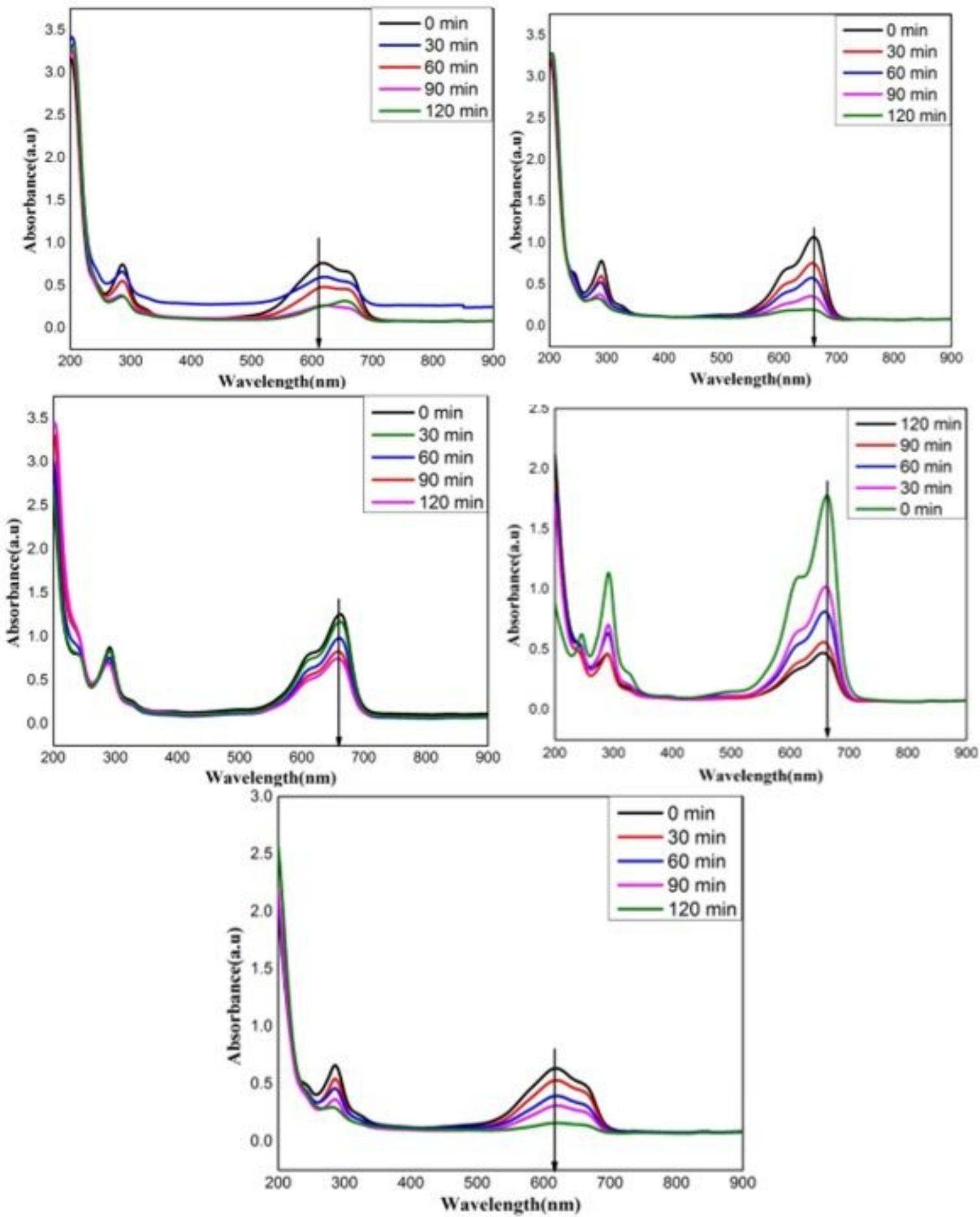

Figure 8

(e1-e5) shows the Absorption spectrum of chemical surfactants based CdO nanoparticles under irradiation of sun light 

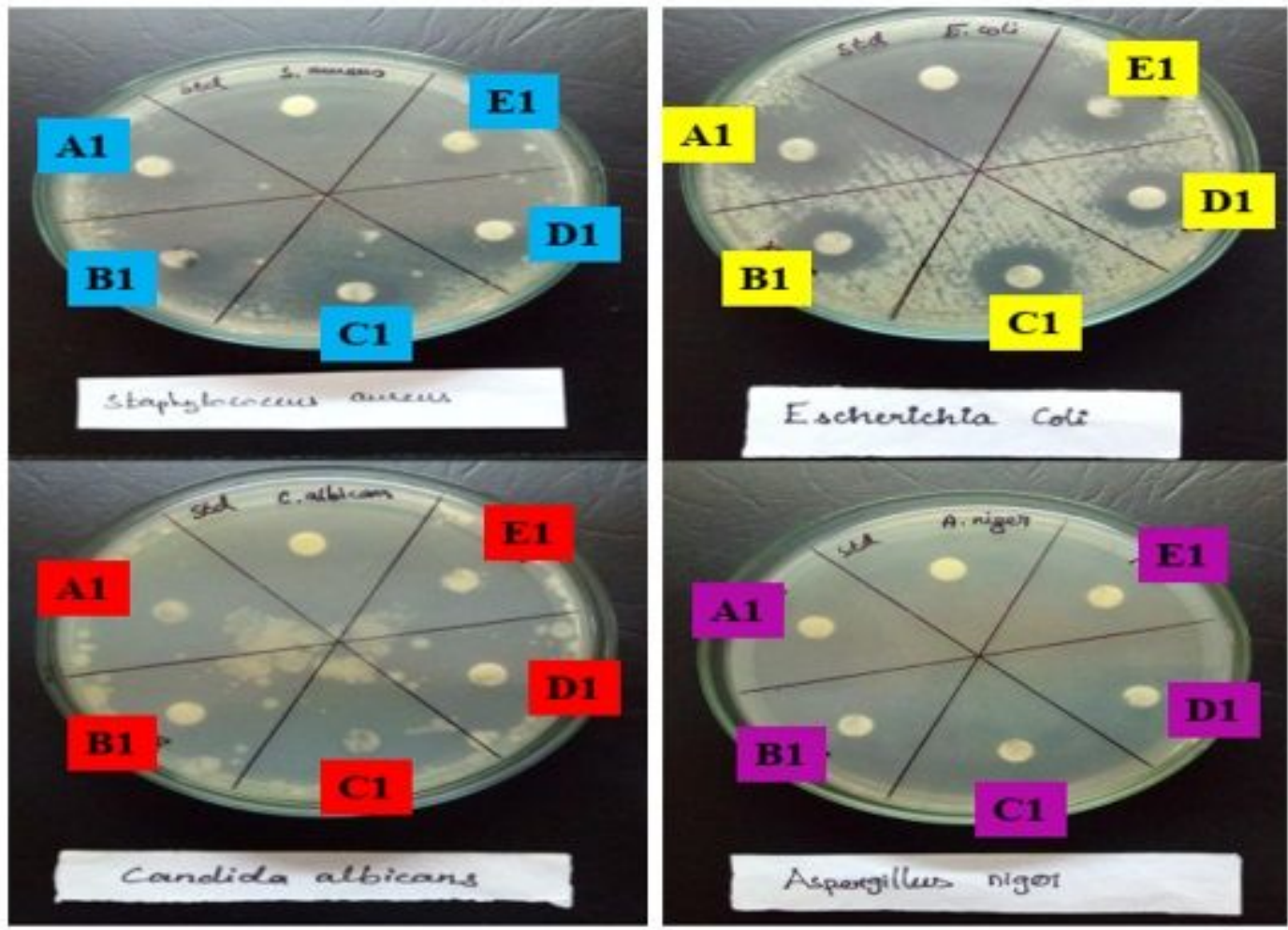

Figure 9

Photograph showing antimicrobial activity of chemical surfactants (A1- n-heptane, B1-Poly imide, C1PVA, D1 - PVP and E1-SDS surfactant based CdO nanoparticles 